\title{
A SYSTEMATIC REVIEW ON AYURVEDIC INTERVENTION FOR KRIMI ROGA OF THE CHILDREN
}

\author{
K T C Dilrukshi \\ Undergraduate student, \\ Institute of Indigenous Medicine, \\ University of Colombo, Sri lanka
}

\author{
Dr. I. A. M. Leena , \\ BAMS ( $1^{\text {st }}$ class Hon) MD (Ay) Pediatrics-India, \\ Senior lecturer, The unit of Study Prasutitantra \\ Kaumarabrutya, Institute of Indigenous Medicine, \\ University Of Colombo, Sri lanka
}

\begin{abstract}
Worm infestations (also known as helminthes infestations) are considered among the most common diseases of children living in the developing countries and one of the main problems. It can be correlated with Krimi roga in Ayurveda. Ayurvedic treatment has been used for krimi roga for centuries and researchers were more prone to done scientific studies about the condition. But systematic review of all RCT $s$ of Ayurveda studies on krimi roga of children has not yet been conducted. For this study data were gathered from following databases PUBMED, Google scholar, AYUSH RESEARCH PORTAL, DHARAONLINE, NCBI, EUROPE, PMC, VIP, CBM etc And from abstract books, Sri Lankan, Indian, international journals. They are Sri Lankan journal of Indigenous Medicine, Ayurveda Sameeksha, Journal of Ayu, The Indian Journal of Medical Research etc. A combination of the following keywords was used: "krimi roga" OR "worm infestation "OR "Ayurveda" OR "Traditional medicine" OR "helminthes" OR "Ayurveda treatment" OR "Ayurveda Therapy" Followed up the database, journals and relevant information were extracted from selected research articles and entered in to a pre structural table and data analyzed was done by using "Jadad Score". Related to the topic Ninety (90) researches were found. Five (5) articles on stool examination, five (5) surveys, eighteen (18) non identical articles, twenty six (26) literature reviews, one (1) case study, three (3) in-vitro studies and Thirty two (32) clinical trials accordingly the topic. So Thirty two (32) articles were identified for possible inclusion in the review. No any researches were shown maximum score possible was five with Jadad score analyzing. Apart from that four studies were marked as maximum score possible was three and taken to further analyzing studies it named as Meta-Analysis. If so, not possible to done Metaanalyzing only followed Jadad Score. Due to poor RCT study designs it is difficult to assess the exact efficacy of Ayurveda treatment for krimi roga. However this review has demonstrated that several Ayurvedic formulae may have the potential to be
\end{abstract}

efficacious in krimi roga of the children. It is highlighted that more research is needed to understand how best to assess and incorporate the methodological quality of primary studies and they are indicated to establish efficacy of the Ayurveda treatments.

Key words: Krimi roga, Ayurvedic treatment, helminthes, traditional, medicine, Ayurveda treatment

\section{INTRODUCTION}

Childhood is considered as the most important phase in life According to Ayurveda samhitha up to 16 years consider as Bala kala which determines the quality of health, wellbeing, learning and behavior across life span. This may be the reason for giving the foremost position for Balachikitsa among Ashtanga (8 branches) of Ayurveda. The regional growth of indigenous medicine gave significant contribution for the development of primary health care [1].

The worm infection is one of the most common pediatric problems especially in developing countries due to the poor hygiene. The most common parasitic infestations caused by Ascaris Lumbricoides. The Ayurveda described worm infestation as Krimi Roga .As per Ayurveda Pureeshaja Krimi can be correlated to the helminthiasis. The Ayurveda prescribe various treatment approaches for the management of Krimi Roga such as; Apakarshana, Prakruti Vighata and Nidana Parivarjana [2]

In Ayurveda the word 'Krimi' is used as broad sense for all worms and microorganisms perspective of modern science. Concept of krimi is not new its description is found since Vedic period. The visible or invisible i, e. macro or microorganisms that affect the living \&nonliving things of biosphere are described in Ayurvedic literature [3]. In modern medical science there is separate branch for worms and microbes eg. Helminthology and microbiology respectively in Ayurveda the word Krimi is used for sookshma krimi, stula krimi and the Ayurveda authentic texts mentioned that the term Krimi and most of the authors described the classification, causes, symptoms and treatment of 
the Krimi [4]. They have described 20 types of krimis and their habitat of the different part of the body, various shapes and size and the location of Shleshmaja and Purisaja Krimis. They produced local as well as general symptoms in human being. Acharyas described Krimi very elaborative way such as different site means of the organism invading in our body and locate in some particular site and produced various diseases specially causing malnutrition in children. Modern science is said that there are some beneficial microorganisms and some are harmful, this is previously mentioned in Samhita period but there is no broad description of beneficial Krimi. For this they are using the word Sahaja Krimi which means avaikarika (non-pathogenic) [5]

Considering about the treatment aspect there is a various procedures mentioned in modern medicine and Ayurveda system of medicine. In modern medical science the condition is managed by use of insecticide, antimicrobial, specific chemotherapy which provides temporary relief and has a number of side effects besides economic and physical

Burden. But in Ayurveda system of medicine the basic principle is break the etiopathogenesis of the diseases. It is very necessary to explore or to clarify pathogenesis to krimi roga based on Ayurvedic principles. Because of the above reason most of people come in search of Ayurveda treatment for intestinal krimi roga of children.

In some research workers had tried to correlate the krimi with few parasites only. The correlation of krimi with the contemporary infectious microbes may be done by examining the resemblance of their habitat, morphology and effect on host, but it is difficult task to correlate of krimi with modern due to lack of detail description of individual krimi.

Researchers were done scientific studies about drugs which were used for krimi roga are Khadiradikashya, Nimbashatakachoorna, krimimudgara rasa, Sanjeevanivati, Kampilllaka choorna are some of them. Most of these studies have suggested their positive effects on this disease condition.

Those studies were published in biomedical journals, various data base in every year by researchers. But the problem is difficult to keep all relevant information practically. In this situation systematic review hold a key position to summarized the state of actual knowledge.

Considering about the Systematic review, Systematic review is appraisal and synthesis of primary research papers using a rigorous and clearly documented methodology in both the search strategy and the selection of studies. They are designed to provide a complete, exhaustive summary of current literature, relevant to a research question. [10]. Systematic reviews of randomized controlled trials are keys in the practice of evidence-based medicine. By doing review of existing studies are often quicker and cheaper than embarking on a new study. In fact systematic review of randomized controlled trial for Ayurveda aspect of krimi roga of children has not yet been conducted.

\section{Why this review is needed}

Worm infestation is fastest growing health problem in children. According to WHO, it is estimated that about $1 / 4^{\text {th }}$ whip worm infestations. Children aged 3-15 years makeup the group with highest worm burden, which is caused greatly due to the contamination of environment, poor sanitation and hygiene. A Parasite is a living organism which depends on a living host for its survival and derives nutrition from the host, without giving any benefit to the host". It is highly prevalent in the poor socioeconomic sector of people. So the management of krimi roga of the children is very essential.

$1 / 4$ of the population are infested with one or more of most common type of parasites [5] Worldwide more than 3.5 billion people are infested with worms out of which 400 million are children among whom 1.47 billion have round worm, 1.3 billion have hook worm and 1.05 billion have By giving beneficial output from the systematic review people may force to studying these things and also they may inferred more broadly than individual studies about the condition. So This Research mainly focuses on the systematic review on Ayurvedic intervention for krimi roga in children. Further In allopathic treatments have lot of side effects therefore people shift to Ayurveda medicine. As well as a lot of researches already have done regarding krimi roga in children in various places, sites, and various people like doctors, lecturers, professors and who related to medical side also

\section{AIMS AND OBJECTIVES}

- To evaluate research studies of Ayurveda treatment for Krimi roga of children

- To analyze and arrange the data in systematic manner.

- To collect and critically analyze multiple research studies according to the qualitative method.

- To study the validity and reliability of Ayurvedic treatment methods regarding balaka krimi roga

\section{METHODOLOGY}

It was conducted in four steps

- STEP 01 Search strategy

- STEP 02 Data recording

- STEP 03 Eligibility assessment and inclusion

- STEP 04 Data synthesis

\section{STEP 01: Search strategy}

Online research (Electronic media) and hand research (printed media) are the suitable source for systematic review. Hand search and electronic search (online) will be used as the methods for data collection. A 
Combination of the following key words is used for the study, Krimi roga "worm infestation "Traditional medicine" "helminthes" "Ayurveda treatment" "Ayurveda Therapy" In this study, researchers that conducted between years 2000-2019 January were selected.

\section{STEP 02: Data recording}

Identified articles were arranged in table using different color cords for categorizing study patterns. Proper recording system was used for record each data while collecting.

\section{STEP 03: Eligibility assessment and inclusion}

Inclusion and exclusion criteria

Only Randomized clinical trials will be included for this review, thus the higher level of evidence with minimal bias is ensured. All the other types of studies will be excluded.

\section{STEP 04: Data synthesis}

\section{Jadad score}

The Jadad score is often used to assess the methodological quality of controlled trials. Studies are scored according to the presence of three key methodology features of clinical trials. In this scale commonly used three item, five-point quality scale was used to rate the quality of the trials. The studies which were formed maximum score possible 3 by using quality assessing scale were taken to further analyzing part. For getting beneficial output those results were included in to statistical method to systematically assess the results of previous research to derived conclusions about the body of research. That was named as MetaAnalysis [13]

\section{OBSERVATION AND RESULTS}

Ninety (90) research studies were found by online searching and hand searching relevant to the topic. From those studies five (5) articles were found as stool examinations, five (5) articles were shown as surveys, eighteen (18) articles weren't identical to the disease condition but mentioned as krimi roga conditions, twenty six (26) articles were found as a Literature, one (01) article was found as a case study. Thirty two (32) articles of clinical studies were identified for possible inclusion in the review

By performed data in pre structural table out of thirty two (32) studies, ten (10) articles couldn't perform any points regarding to the methodological quality assessing. Fourteen (14) was performed 01 points, three (03) articles were shown 02 points, four (4) were shown 03 points; Any articles couldn't performed 04 points and 05 points

Out of thirty two (32) studies seven (07) articles were shown 2-5 score possible for inclusion (minimum score possible was 2 and maximum score possible was 5 regarding to the Jadad score) and twenty four (24) were formed less than 2 score possible.

Apart from that four (4)studies were marked as maximum score possible was three (3)studies (2 points)by using quality assessing scale (Jaded Score) and taken to further analyzing studies it named as MetaAnalysis. According to the topic there were not found Cresearches maximum score five (5). Besides maximum score three (3), there are three (3) researches marked as maximum score two (2) investigated the effects of different Ayurvedic interventions namely Krimighna kashaya vat $i$, vidanga krishnadi kashaya, krimighna dashemani etc. They are mentioned below.

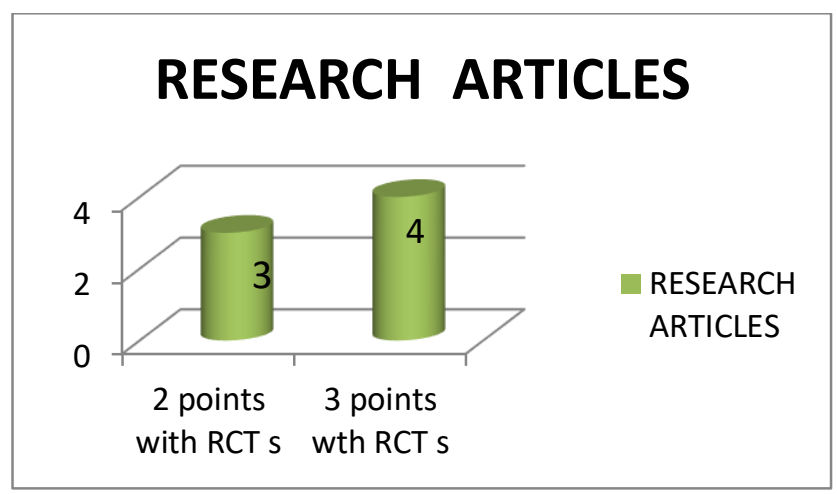

Results of score possible to include MA

A meta-analysis (MA) is a statistical analysis that combines the results of multiple scientific studies. Meta-analysis can be performed when there are multiple scientific studies addressing the same question, meta-analysis has the capacity to contrast results from different studies and identify patterns among study results, sources of disagreement among those results, or other interesting relationships that may come to light in the context of multiple studies. [14]

\section{DISCUSSION}

Individual research studies are often not big and powerful enough to provide reliable answers on their own or several studies on the effects of a treatment might come to different conclusions. In order to find reliable answers to research questions, have to look at all of the studies and analyze their results together. By giving beneficial output from systematic review people may force to studying these things and also they may inferred more broadly than individual studies about the condition.

Discussing about the review, challenges were occurred when searching articles from sources, analyzing with Jadad score and data including for performed metaanalyzing. Publication bias, having insufficient data, deprived explanation, poor labeling about control group and study group are some example for doubts in this research. And also some are failed to performed proper 


\section{International Journal of Engineering Applied Sciences and Technology, 2020 \\ Vol. 5, Issue 4, ISSN No. 2455-2143, Pages 26-31 \\ Published Online August 2020 in IJEAST (http://www.ijeast.com)}

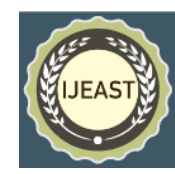

randomization, inclusion, exclusion criteria of randomization with descriptions. Most were done as open label studies or open observational studies or single arm clinical study or single blind and also some are doesn't mention about the withdrawals too. In some clinical studies placebo has mentioned but none of them are double-blind. Some researchers were randomized but no evidence of randomized method.

In this research study, we were expected to find a methodological quality of the clinical studies done for Ayurvedic treatment on krimi roga of the children. Doing a research with a methodological quality is help to diminish errors. Because methodological errors such as poor blinding or poor randomization allow factors such as placebo effect or selection bias adversely affect to the results of a trial.

Worldwide many scales are used to evaluate the methodological quality of RCTs, but most of these scales have not been adequately developed and have not been adequately tested for validity and reliability. From identified scales that used to evaluate the methodological quality of RCTs the Jadad scale presented the best validity and reliability evidence

\section{Distribution of data}

Term of randomization

- 21 studies were mentioned

- 11 were not mentioned

Description of randomization

7 were mentioned in detail

(Coin toss, lottery method, loss of dice, shuffling cards, random numbers table, electronic digital randomization table)

Double blinding and description * no studies were mentioned

\section{Description of withdrawal \\ - 5 were mentioned \\ - 27 were not mentioned}

Usage of other blinding method

(single blind, open observational, open label, single arm

clinicalstudy)

As an another result of this review -Ayurveda aspect of management of krimi roga of children, Acharyas was mentioned in detail description of line of treatment. Considering above 32 of RCTs they were mainly categorized in to 3 types of management (Nidana parivarjana, Prakruti vighata, krimi apakarshana) Among these, Apakarshana (Samshodhana Chikitsa) considering the patients mostly pediatric age group of patients inability to undergo vigorous processes of
Samshodhana Karma of the degree advised by Charaka and Nidana Parivarjana is the general line of treatment is adoptable in all group of patients. So remain specific treatment Prakriti Vighata - it should be such a way that it is cost effective with minimum dose, period, and easy direction and with no side effects. According to 32 clinical trials, Prakruti vighata treatment method were used in $90 \%$ of research studies, Nidana parivarjana (8\%of studies), Krimi apakarshana (samshodana)-2\% of clinical trials.

According to the Jadad score five-point quality scale was used to rate the quality of the trials the minimum score possible for inclusion of a study in the review was 02 and maximum score possible was 05. According to my research findings anyone has not done any most qualitative clinical trial on intestinal krimi roga of children related to the jaded score Considering about the whole result that given by Jadad scale, four (4) clinical studies were showed maximum score three (3) possible. So, these four were the most valuable and reliable studies. Others were failed to performed proper randomization, inclusion and exclusion criteria of randomization. All the side effects described in some studies are mild and self- limited and also long term safety of herbal medicine has not been established.

And also most of studies given the result as statistically, they categorized the data according to the symptoms relieves while doing the procedure. As example Symptomatic relief during the treatment with decoction of Leucas zeylanica and placebo(pain in the abdomen, impaired appetite,constipation, fever, eructation ,itching in anal region, bad breath, dryness of skin...etc. those symptoms were varying to each studies. That is a problem faced when gather results for meta-analyzing part in this study. Some researchers are categorized according to quality of stool wise, type of worm, distribution of the patients according to play habit, family wise, personal hygiene, sharirika prakruti etc.

Most of studies were not done for each type of pureeshaja krimi separately. Some were performed to demonstrate the effectiveness of the drug for each type of pureeshaja krimi(Ascaris lumbricoides, Hymenolepsisnana, Trichuris trichiura, Entameoba histolytica)In most of the studies study group and control group that found from online and hand searching were difficult to compare. Because the drug formulas used for two groups are different. Control group was used different drug formula with different dosage form and mode of administration. Not a placebo at all.But in most of the studies subjects treated with Ayurvedic formulae showed statistically significant improvement compared with the comparator drug. And also they mentioned symptomatically improvement too.

Finally to complete the systematic review, tried to done meta-analysis for the research studies with help of results. But due to insufficient data collection from studies couldn't performed effect size estimate and 


\section{International Journal of Engineering Applied Sciences and Technology, 2020 \\ Vol. 5, Issue 4, ISSN No. 2455-2143, Pages 26-31 \\ Published Online August 2020 in IJEAST (http://www.ijeast.com)}

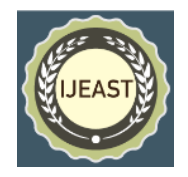

graphically display relevant to the topic. If so, not possible to done Meta-analyzing only followed Jadad Score in this research study. Considering all the researches my recommendation is the all should know (who do researches) the jaded scale before perform the research studies.

\section{CONCLUSION}

Out of thirty (32) research articles four (4) are maximum points achieved (3 points) to the quality assessing scale(Jadad Score), not due to metaanalyzing. These four were done with proper randomization and mentioned about dropouts but double blinding with description was not mentioned.

However this review has demonstrated that several of Ayurvedic formulae may have the potential to be efficacious in reducing the signs and symptoms of intestinal krimi roga with relatively few side effects.

Believed that more research is needed to understand how best to assess and incorporate the methodological quality of primary studies and they are indicated to establish efficacy of the Ayurvedic treatments.

\section{ACKNOWLEDGMENT}

Working on this project on "A SYSTEMATIC REVIEW ON AYURVEDA INTERVENTION FOR KRIMI ROGA OF THE CHILDREN" was a source of immense knowledge to me. I would like to give my gratitude to my supervisor Dr I A M Leena who has given me intensive guidance and creative recommendations throughout this research. I wish to convey my special thanks to Dr W A S S Weerakoon, head of the department of Prasutitantra Kaumarabhritya and, I take this valuable opportunity to thank academic staffs of department of Prasutitantra Kaumarabhritya who involved for arrangements of this research project. Special thank goes to all colleagues for devoting time to make some valuable discussions, suggestions and guidance about this project and to provide necessary documents time to time. Thanks to all library staff and IT laboratory staff IIM UOC, all who directly and indirectly support to do this work and all researchers who published those researches which I used in my study.

Finally my very special thanks and appreciation goes to my parents for their love and support. I am also extremely thankful to my supervisor Dr I A M Leena

\section{REFERENCES}

1. Meena M K, (2017), A Review on the Ayurvedic Management of Krimi (Intestinal worms) in Children,Available from:http://oaji.net/pdf.html?n=2017/17911543252956.pdf

2. Mapari A S, Suryavanshi V,(2017) Ayurveda perspective of krimi roga w.s.r.to pureesha ja krimi:A literature review,World journal of pharmaceutical and medical research, Available from;www.wjpmr.com

3. Mapari A S, Suryavanshi V,(2017) Ayurveda perspective of krimi roga w.s.r.to pureeshaja krimi: A literature review,World journal of pharmaceutical and medical research, Available from;www.wjpmr.com

4. SiddiquiS, Patni K 2.(2018) Dept. of Kaumarabhritya, State Ayurvedic College \& Hospital, Lucknow (U.P.), Dept. of Kaumarabhritya, State Ayurvedic College \& Hospital, Lucknow (U.P.), India,A review on ayurvedic concept of krimi and its management, Available from:www.ijrap.net

5. SiddiquiS,Patni K 2,(2018) Dept. of Kaumarabhritya, State Ayurvedic College \& Hospital, Lucknow (U.P.), Dept. of Kaumarabhritya, State Ayurvedic College \& Hospital, Lucknow (U.P.), India, A review on ayurvedic concept of krimi and its management,Available from:www.ijrap.net

6. Kumarasingha A, MadawaNidana, Purwakanda,(1984)10 ${ }^{\text {th }}$ chapter,forthslok, on worm infestation Department of Ayurveda, Sri Lanka,(pg213)

7. Kumarasingha A, MadawaNidana, Purwakanda,(1984)10 ${ }^{\text {th }}$ chapter,forthslok, on worm infestation Department of Ayurveda, Sri Lanka,,(Pg214)

8. Siddiqui S, Patni K 2 (2018) Dept. of Kaumarabhritya, State Ayurvedic College \& Hospital, Lucknow (U.P.), Dept. of Kaumarabhritya, State Ayurvedic College \& Hospital, Lucknow (U.P.), India,,A review on ayurvedic concept of krimi and its management, Available from:www.ijrap.net

9. Niraj S,Nitin P, VarshaS,(2018), Worm infestation in ayurveda and modern science:Approachandmanagement,Availablefrom;h ttp://www.theyogicjournal.com/ pdf/2018/vol3issue2/PartE/3-2-28-513.pdf

10. CrombieIK,(2019)Whatissystematicreview,Availab lefrom:https://libguides.library.curtin.edu.au/c.php? $\mathrm{g}=202420 \& \mathrm{p}=1332858$ 
11. Jadad et al.( 1996 Feb;17)(1):1-12 Assessing the quality of reports of randomized clinical trials: is blinding necessary, Control Clinic Trials.

12. Halpem S H, Douglas M J (2005) Jadad scale for reportingrandomizedcontrolledtrials, Availablefrom :https://onlinelibrary.wiley.com/doi/pdf/10.1002/97 80470988343.app1

13. Halpem S H, Douglas M J (2005), Jadadscale for reportingrandomizedcontrolledtrials, Availablefrom :https://onlinelibrary.wiley.com/doi/pdf/10.1002/97 80470988343.app1 